\title{
Risk factor analysis for predicting cervical lymph node metastasis in papillary thyroid carcinoma: a study of 966 patients
}

\author{
Chenxi Liu, Cheng Xiao, Jianjia Chen, Xiangyang Li, Zijian Feng, Qiyuan Gao and Zhen Liu* (0)
}

\begin{abstract}
Backgrounds: The aim of this study is to investigate the risk factors for the cervical lymph node metastasis in papillary thyroid carcinoma (PTC).

Methods: The clinicopathological data from the 966 PTC patients who underwent thyroid operation between January 2013 and December 2015 in the general surgery department of Shengjing Hospital of China Medical University were collected. The risk factors of predicting cervical lymph node metastasis were analyzed.

Results: Male, age $\leq 45$ years old, tumor size $>1.0 \mathrm{~cm}$, extrathyroidal extension (ETE), US features as microcalcification, were independent risk factors for central lymph node metastasis (CLNM) $(P<0.05)$. Only CLNM was independent risk factors for lateral lymph node metastasis (LLNM) $(P<0.05)$. The ROC curve showed that the cutoff value of the number of CLNM for predicting lateral lymph node metastasis was defined as 2.5 (Sensitivity= 0.535 , Specificity $=0.722$, AUC $=0.669, P<0.05$ ). When the number of $C L N M>3$, OR value was significantly higher, suggesting that the risk of LLNM increased significantly. The incidence of LLNM in level III (66.8\%) and level IV (67.3\%) were significantly higher than level II (42.2\%) and level V (21.3\%) $(P<0.05)$. The incidence of LLNM and skip metastasis in tumor located in the upper $1 / 3$ of the lobe was the highest $(P<0.05)$.

Conclusions: Prophylactic central lymph node dissection should be performed in patients with risk factors as male, age $\leq 45$ years old, tumor size $>1.0 \mathrm{~cm}$, ETE and US features as microcalcification. Lateral lymph node dissection (LLND) should be more actively performed in patients with the number of CLNM>3. Extent of LLND should include levels II, III, IV and V. Tumor located in the upper 1/3 of the lobe was vulnerable for LLNM and skip metastasis, so lymph node in lateral compartment should be noticed when lymph node status was preoperatively evaluated by imaging examination.
\end{abstract}

Keywords: Papillary thyroid carcinoma, Lymph node metastasis, Risk factor

\section{Background}

Thyroid carcinoma is the most common kind of malignant endocrine tumor, accounts for $1 \%$ of all human malignant tumors and $33 \%$ of the head and neck malignant tumors. Among the thyroid carcinoma, $80-85 \%$ are papillary thyroid carcinoma (PTC) [1]. The incidence of cervical lymph node metastasis in PTC can reach to 4090\% [1]. Cervical lymph node metastasis was the main risk factor for a higher recurrence in PTC patient $[2,3]$. In general, the lymph node metastasis of PTC occurs in central compartment first, then expands to the lateral compartment $[4,5]$, but it also has the properties of skip metastasis. Therefore, a reasonable and comprehensive initial surgical treatment can decrease the recurrence rate and the reoperation complications. In this study we retrospectively analyzed the clinicopathological data of 966 PTC patients, summarized the features and the risk factors for cervical lymph node metastasis, to help making a reasonable surgical plan and achieve the best treatment effectiveness.

* Correspondence: liuzhen1973@aliyun.com

Department of General Surgery, Shengjing Hospital of China Medical

University, No.36 Sanhao Street, Shenyang 100004, China

(c) The Author(s). 2019 Open Access This article is distributed under the terms of the Creative Commons Attribution 4.0 International License (http://creativecommons.org/licenses/by/4.0/), which permits unrestricted use, distribution, and

reproduction in any medium, provided you give appropriate credit to the original author(s) and the source, provide a link to the Creative Commons license, and indicate if changes were made. The Creative Commons Public Domain Dedication waiver (http://creativecommons.org/publicdomain/zero/1.0/) applies to the data made available in this article, unless otherwise stated. 
Table 1 Demographics and clinical characteristics of patients undergoing central lymph node dissection

\begin{tabular}{|c|c|c|c|c|c|c|}
\hline \multirow[t]{2}{*}{$\begin{array}{l}\text { Clinicopathological } \\
\text { properties }\end{array}$} & & \multirow[b]{2}{*}{ Total } & \multicolumn{4}{|c|}{$\begin{array}{l}\text { Central lymph node } \\
\text { metastasis }\end{array}$} \\
\hline & & & \multicolumn{2}{|l|}{ No } & \multicolumn{2}{|l|}{ Yes } \\
\hline Subjects, $n$ & & 966 & 599 & $62.0 \%$ & 367 & $38.0 \%$ \\
\hline \multirow[t]{2}{*}{ Gender } & Female & 772 & 496 & $64.2 \%$ & 276 & $35.8 \%$ \\
\hline & Male & 194 & 103 & $53.1 \%$ & 91 & $46.9 \%$ \\
\hline \multirow[t]{4}{*}{ Age (years) } & $\leq 35$ & 229 & 97 & $42.4 \%$ & 132 & $57.6 \%$ \\
\hline & $35-45$ & 248 & 146 & $58.9 \%$ & 102 & $41.1 \%$ \\
\hline & $45-55$ & 273 & 193 & $70.7 \%$ & 80 & $29.3 \%$ \\
\hline & $>55$ & 216 & 163 & $75.5 \%$ & 53 & $24.5 \%$ \\
\hline \multirow[t]{4}{*}{ Tumor size $(\mathrm{cm})$} & $\leq 0.5$ & 178 & 145 & $81.5 \%$ & 33 & $18.5 \%$ \\
\hline & $0.5-1.0$ & 363 & 255 & $70.2 \%$ & 108 & $29.8 \%$ \\
\hline & $1.0-2.0$ & 275 & 140 & $50.9 \%$ & 135 & $49.1 \%$ \\
\hline & $>2.0$ & 150 & 59 & $39.3 \%$ & 91 & $60.7 \%$ \\
\hline \multicolumn{7}{|l|}{ Ultrasound feature } \\
\hline \multirow[t]{2}{*}{ Microcalcification } & No & 706 & 459 & $65.0 \%$ & 247 & $35.0 \%$ \\
\hline & Yes & 260 & 140 & $53.8 \%$ & 120 & $46.2 \%$ \\
\hline \multirow[t]{2}{*}{ Hypoechoic solid nodules } & No & 183 & 112 & $61.2 \%$ & 71 & $38.8 \%$ \\
\hline & Yes & 783 & 487 & $62.2 \%$ & 296 & $37.8 \%$ \\
\hline \multirow[t]{2}{*}{ Irregular shape } & No & 631 & 401 & $63.5 \%$ & 230 & $36.5 \%$ \\
\hline & Yes & 335 & 198 & $59.1 \%$ & 137 & $40.9 \%$ \\
\hline \multirow[t]{2}{*}{ Infiltrative margins } & No & 252 & 158 & $62.7 \%$ & 94 & $37.3 \%$ \\
\hline & Yes & 714 & 441 & $61.8 \%$ & 273 & $38.2 \%$ \\
\hline \multirow[t]{2}{*}{ Intra-nodular vascularity } & No & 328 & 228 & $69.5 \%$ & 100 & $30.5 \%$ \\
\hline & Yes & 638 & 371 & $58.2 \%$ & 267 & $41.8 \%$ \\
\hline \multirow[t]{2}{*}{ Multifocality } & No & 679 & 439 & $64.7 \%$ & 240 & $35.3 \%$ \\
\hline & Yes & 287 & 160 & $55.7 \%$ & 127 & $44.3 \%$ \\
\hline \multirow[t]{2}{*}{ Bilateral } & No & 767 & 491 & $64.0 \%$ & 276 & $36.0 \%$ \\
\hline & Yes & 199 & 108 & $54.3 \%$ & 91 & $45.7 \%$ \\
\hline \multirow[t]{2}{*}{ Extrathyroidal extension } & No & 759 & 500 & $65.9 \%$ & 259 & $34.1 \%$ \\
\hline & Yes & 207 & 99 & $47.8 \%$ & 108 & $52.2 \%$ \\
\hline \multirow[t]{2}{*}{ Distant metastasis } & No & 961 & 598 & $62.2 \%$ & 363 & $37.8 \%$ \\
\hline & Yes & 5 & 1 & $20.0 \%$ & 4 & $80.0 \%$ \\
\hline \multirow[t]{2}{*}{ Hashimoto's thyroiditis } & No & 604 & 384 & $63.6 \%$ & 220 & $36.4 \%$ \\
\hline & Yes & 362 & 215 & $59.4 \%$ & 147 & $40.6 \%$ \\
\hline TSH value & & & \multicolumn{2}{|c|}{$2.10 \pm 1.65$} & \multicolumn{2}{|c|}{$2.13 \pm 1.49$} \\
\hline
\end{tabular}

\section{Methods}

\section{Patients}

The study was approved by the Ethical Committee of Shengjing Hospital of China Medical University. We enrolled the patients who underwent the initial thyroid operation in the general surgery department of Shengjing Hospital and were pathologically proved as PTC between January 2013 and December 2015. We excluded the patients with other types of thyroid malignant tumor, without central lymph node dissection (CLND), with the history of thyroid operation, or with incomplete data. There were 966 patients qualified and enrolled in this study.

\section{Operation approach}

Thyroid nodules and cervical lymph nodes were assessed by ultrasound in all patients before surgery. Cervical contrast enhanced computed tomography $(\mathrm{CT})$ and fine needle aspiration (FNA) were not routinely performed during this study and were only used in very few patients. The histology of the frozen sections were performed during the surgical procedures for all the tumors. For the unilateral lobe PTC, lobectomy plus isthmusectomy with ipsilateral CLND was performed; if nodule was detected in the contralateral lobe, total thyroidectomy was performed in our hospital. For the isthmus or bilateral PTC, total thyroidectomy plus bilateral CLND was performed. If lateral lymph node metastasis (LLNM) is evident on preoperative imaging exam or proved by fine needle aspiration cytology, a functional lateral lymph node dissection (LLND) would be performed.

\section{Clinicopathological properties}

The following clinicopathological properties were studied to analyze the risk factors for the CLNM: gender, age, preoperative TSH level, unilateral/bilateral location of tumors in the lobes, the number and size of tumor, with or without extrathyroidal extension (ETE), distant metastasis, or Hashimoto's thyroiditis (HT), or US features including microcalcification, hypoechoic solid nodules, irregular shape, infiltrative margins, and intranodular vascularity. In addition to the above variables, the status of central lymph node was also considered as a clinicopathological property for analyzing the risk factors for the LLNM. Solitary was defined as one tumor in the thyroid, multifocality was defined as two or more tumors in the thyroid. Tumor size was defined as the maximal diameter in solitary case, and was defined as the maximal diameter of the largest tumor in the multifocality cases. ETE was defined as invading strap muscle, larynx, trachea, esophagus, recurrent laryngeal nerve, prevertebral fascia, encasing carotid artery or mediastinal vessels. TSH level was measured within one month before surgery in our hospital, and the normal range was $0.3-4.8 \mathrm{uIU} / \mathrm{mL}$. The HT patients were diagnosed with any one of the following criteria: positive for antithyroid peroxidase (TPO) antibody; positive for antithyroglobulin antibody; pathologic confirmation of HT [6].

\section{Statistics analysis}

Software SPSS 17.0 was used for statistics analysis. Univariate analysis was performed with univariate logistic models, and variables with statistical significance in 
Table 2 Univariate analysis of risk factors for central lymph node metastasis

\begin{tabular}{|c|c|c|c|c|c|}
\hline & & OR & $95 \% \mathrm{Cl}$ & & $P$ value \\
\hline & & & Lower & Upper & \\
\hline Gender & (male vs. female) & 1.59 & 1.16 & 2.18 & 0.004 \\
\hline Age (years) & & & & & $<0.001^{\mathrm{a}}$ \\
\hline & $\leq 35$ & 4.19 & 2.79 & 6.28 & $<0.001$ \\
\hline & $35-45$ & 2.15 & 1.44 & 3.51 & $<0.001$ \\
\hline & $45-55$ & 1.28 & 0.85 & 1.91 & 0.240 \\
\hline & $>55$ & 1 & & & \\
\hline Tumor size $(\mathrm{cm})$ & & & & & $<0.001^{\mathrm{a}}$ \\
\hline & $\leq 0.5$ & 1 & & & \\
\hline & $0.5-1.0$ & 1.86 & 1.20 & 2.89 & 0.006 \\
\hline & $1.0-2.0$ & 4.24 & 2.71 & 6.62 & $<0.001$ \\
\hline & $>2.0$ & 6.78 & 4.11 & 11.18 & $<0.001$ \\
\hline Ultrasound feature & & & & & \\
\hline Microcalcification & (yes vs. no) & 1.59 & 1.19 & 2.13 & 0.002 \\
\hline Hypoechoic solid nodules & (yes vs. no) & 0.96 & 0.69 & 1.33 & 0.803 \\
\hline Irregular shape & (yes vs. no) & 1.21 & 0.92 & 1.58 & 0.176 \\
\hline Infiltrative margins & (yes vs. no) & 1.04 & 0.77 & 1.40 & 0.793 \\
\hline Intra-nodular vascularity & (yes vs. no) & 1.64 & 1.24 & 2.18 & 0.001 \\
\hline Multifocality & (yes vs. no) & 1.45 & 1.10 & 1.92 & 0.009 \\
\hline Bilateral & (yes vs. no) & 1.50 & 1.09 & 2.06 & 0.012 \\
\hline Extrathyroidal extension & (yes vs. no) & 2.11 & 1.54 & 2.88 & $<0.001$ \\
\hline Distant metastasis & (yes vs. no) & 6.59 & 0.73 & 59.19 & 0.092 \\
\hline Hashimoto's thyroiditis & (yes vs. no) & 1.19 & 0.91 & 1.56 & 0.195 \\
\hline TSH value & & 1.01 & 0.93 & 1.10 & 0.799 \\
\hline
\end{tabular}

${ }^{a}$ means the global $p$-values

Table 3 Multivariate analysis of risk factors for central lymph node metastasis

\begin{tabular}{|c|c|c|c|c|c|}
\hline & & \multirow[t]{2}{*}{ OR } & \multicolumn{2}{|l|}{$95 \% \mathrm{Cl}$} & \multirow[t]{2}{*}{$P$ value } \\
\hline & & & Lower & Upper & \\
\hline Gender & (male vs. female) & 1.48 & 1.04 & 2.11 & 0.028 \\
\hline \multirow[t]{5}{*}{ Age (years) } & & & & & $<0.001^{\mathrm{a}}$ \\
\hline & $\leq 35$ & 4.83 & 3.11 & 7.48 & $<0.001$ \\
\hline & $35-45$ & 2.62 & 1.70 & 4.04 & $<0.001$ \\
\hline & $45-55$ & 1.50 & 0.97 & 2.32 & 0.066 \\
\hline & $>55$ & 1 & & & \\
\hline \multirow[t]{5}{*}{ Tumor size(cm) } & & & & & $<0.001^{\mathrm{a}}$ \\
\hline & $\leq 0.5$ & 1 & & & \\
\hline & $0.5-1.0$ & 1.55 & 0.98 & 2.46 & 0.060 \\
\hline & $1.0-2.0$ & 3.22 & 2.00 & 5.18 & $<0.001$ \\
\hline & $>2.0$ & 4.85 & 2.81 & 8.35 & $<0.001$ \\
\hline Microcalcification & (yes vs. no) & 1.43 & 1.04 & 1.97 & 0.029 \\
\hline Intra-nodular vascularity & (yes vs. no) & 1.30 & 0.95 & 1.78 & 0.100 \\
\hline Multifocality & (yes vs. no) & 0.96 & 0.59 & 1.59 & 0.886 \\
\hline Bilateral & (yes vs. no) & 1.39 & 0.80 & 2.41 & 0.242 \\
\hline Extrathyroidal extension & (yes vs. no) & 1.68 & 1.18 & 2.39 & 0.004 \\
\hline
\end{tabular}

${ }^{a}$ means the global $p$-values 
Table 4 Demographics and clinical characteristics of patients undergoing lateral lymph node dissection

\begin{tabular}{|c|c|c|c|c|c|c|}
\hline \multirow{2}{*}{$\begin{array}{l}\text { Clinicopathological } \\
\text { properties }\end{array}$} & & \multirow[b]{2}{*}{ Total } & \multicolumn{4}{|c|}{ Lateral lymph node metastasis } \\
\hline & & & \multicolumn{2}{|l|}{ No } & \multicolumn{2}{|l|}{ Yes } \\
\hline Subjects, $n$ & & 420 & 209 & $49.8 \%$ & 211 & $50.2 \%$ \\
\hline \multirow[t]{2}{*}{ Gender } & Female & 329 & 172 & $52.3 \%$ & 157 & $47.7 \%$ \\
\hline & Male & 91 & 37 & $40.7 \%$ & 54 & $59.3 \%$ \\
\hline \multirow[t]{4}{*}{ Age (years) } & $\leq 35$ & 121 & 48 & $39.7 \%$ & 73 & $60.3 \%$ \\
\hline & $35-45$ & 104 & 52 & $50.0 \%$ & 52 & $50.0 \%$ \\
\hline & $45-55$ & 108 & 56 & $51.9 \%$ & 52 & $48.1 \%$ \\
\hline & $>55$ & 87 & 53 & $60.9 \%$ & 34 & $39.1 \%$ \\
\hline \multirow[t]{4}{*}{ Tumor size $(\mathrm{cm})$} & $\leq 0.5$ & 35 & 24 & $68.6 \%$ & 11 & $31.4 \%$ \\
\hline & $0.5-1.0$ & 137 & 82 & $59.9 \%$ & 55 & $40.1 \%$ \\
\hline & $1.0-2.0$ & 147 & 69 & $46.9 \%$ & 78 & $53.1 \%$ \\
\hline & $>2.0$ & 101 & 34 & $33.7 \%$ & 67 & $66.3 \%$ \\
\hline \multicolumn{7}{|l|}{ Ultrasound feature } \\
\hline \multirow[t]{2}{*}{ Microcalcification } & No & 277 & 144 & $52.0 \%$ & 133 & $48.0 \%$ \\
\hline & Yes & 143 & 65 & $45.5 \%$ & 78 & $54.5 \%$ \\
\hline \multirow[t]{2}{*}{ Hypoechoic solid nodules } & No & 73 & 33 & $45.2 \%$ & 40 & $54.8 \%$ \\
\hline & Yes & 347 & 176 & $50.7 \%$ & 171 & $49.3 \%$ \\
\hline \multirow[t]{2}{*}{ Irregular shape } & No & 259 & 131 & $50.6 \%$ & 128 & $49.4 \%$ \\
\hline & Yes & 161 & 78 & $48.4 \%$ & 83 & $51.6 \%$ \\
\hline \multirow[t]{2}{*}{ Infiltrative margins } & No & 95 & 48 & $50.5 \%$ & 47 & $49.5 \%$ \\
\hline & Yes & 325 & 161 & $49.5 \%$ & 164 & $50.5 \%$ \\
\hline \multirow[t]{2}{*}{ Intra-nodular vascularity } & No & 114 & 57 & $50.0 \%$ & 57 & $50.0 \%$ \\
\hline & Yes & 306 & 152 & $49.7 \%$ & 154 & $50.3 \%$ \\
\hline \multirow[t]{2}{*}{ Multifocality } & No & 272 & 142 & $52.2 \%$ & 130 & $47.8 \%$ \\
\hline & Yes & 148 & 67 & $45.3 \%$ & 81 & $54.7 \%$ \\
\hline \multirow[t]{2}{*}{ Bilateral } & No & 315 & 163 & $51.7 \%$ & 152 & $48.3 \%$ \\
\hline & Yes & 105 & 46 & $43.8 \%$ & 59 & $56.2 \%$ \\
\hline \multirow[t]{2}{*}{ Extrathyroidal extension } & No & 286 & 153 & $53.5 \%$ & 133 & $46.5 \%$ \\
\hline & Yes & 134 & 56 & $41.8 \%$ & 78 & $58.2 \%$ \\
\hline \multirow[t]{2}{*}{ Distant metastasis } & No & 416 & 207 & $49.8 \%$ & 209 & $50.2 \%$ \\
\hline & Yes & 4 & 2 & $50.0 \%$ & 2 & $50.0 \%$ \\
\hline \multirow[t]{2}{*}{ Hashimoto's thyroiditis } & No & 251 & 130 & $51.8 \%$ & 121 & $48.2 \%$ \\
\hline & Yes & 169 & 79 & $46.7 \%$ & 90 & $53.3 \%$ \\
\hline \multirow[t]{2}{*}{ The number of CLNM } & 0 & 186 & 130 & $69.9 \%$ & 56 & $30.1 \%$ \\
\hline & $\begin{array}{c}1-3 \\
>3\end{array}$ & $\begin{array}{l}165 \\
69\end{array}$ & $\begin{array}{l}68 \\
11\end{array}$ & $\begin{array}{l}41.2 \% \\
15.9 \%\end{array}$ & $\begin{array}{l}97 \\
58\end{array}$ & $\begin{array}{l}58.8 \% \\
84.1 \%\end{array}$ \\
\hline TSH value & & & \multicolumn{2}{|c|}{$2.20 \pm 1.66$} & \multicolumn{2}{|c|}{$2.16 \pm 1.44$} \\
\hline
\end{tabular}

univariate analysis were further included in the multivariate logistic models. The multivariate analysis was performed with binary logistic regression analysis to assess independent risk factors for CLNM and LLNM. ROC curve was used to determine the critical value of the number of CLNM for predicting LLNM. Differences were assessed with the chi-square test for categorical variables. Measurement data such as TSH level, the average age and the average tumor size was presented as mean \pm standard deviation. Statistical significance was considered when $P<0.05$.

\section{Results}

Patients' characteristics

Among the 966 cases, including 194 men and 772 women, the average age was $45 \pm 12$ years old (ranging 
Table 5 Univariate analysis of risk factors for lateral lymph node metastasis

\begin{tabular}{|c|c|c|c|c|c|}
\hline & & \multirow[t]{2}{*}{ OR } & \multicolumn{2}{|l|}{$95 \% \mathrm{Cl}$} & \multirow[t]{2}{*}{$P$ value } \\
\hline & & & Lower & Upper & \\
\hline Gender & (male vs. female) & 1.60 & 1.00 & 2.56 & 0.051 \\
\hline \multirow[t]{5}{*}{ Age (years) } & & & & & $0.025^{a}$ \\
\hline & $\leq 35$ & 2.37 & 1.35 & 4.17 & 0.003 \\
\hline & $35-45$ & 1.56 & 0.88 & 2.78 & 0.132 \\
\hline & $45-55$ & 1.45 & 0.82 & 2.57 & 0.206 \\
\hline & $>55$ & 1 & & & \\
\hline \multirow[t]{5}{*}{ Tumor size(cm) } & & & & & $<0.001^{\mathrm{a}}$ \\
\hline & $\leq 0.5$ & 1 & & & \\
\hline & $0.5-1.0$ & 1.46 & 0.66 & 3.23 & 0.346 \\
\hline & $1.0-2.0$ & 2.47 & 1.13 & 5.40 & 0.024 \\
\hline & $>2.0$ & 4.30 & 1.89 & 9.81 & 0.001 \\
\hline \multicolumn{6}{|l|}{ Ultrasound feature } \\
\hline Microcalcification & (yes vs. no) & 1.30 & 0.87 & 1.95 & 0.205 \\
\hline Hypoechoic solid nodules & (yes vs. no) & 0.80 & 0.48 & 1.33 & 0.392 \\
\hline Irregular shape & (yes vs. no) & 1.09 & 0.74 & 1.61 & 0.671 \\
\hline Infiltrative margins & (yes vs. no) & 1.04 & 0.66 & 1.64 & 0.865 \\
\hline Intra-nodular vascularity & (yes vs. no) & 1.01 & 0.66 & 1.56 & 0.953 \\
\hline Multifocality & (yes vs. no) & 1.32 & 0.88 & 1.97 & 0.175 \\
\hline Bilateral & (yes vs. no) & 1.38 & 0.88 & 2.15 & 0.160 \\
\hline Extrathyroidal extension & (yes vs. no) & 1.60 & 1.06 & 2.43 & 0.026 \\
\hline Distant metastasis & (yes vs. no) & 0.99 & 1.38 & 7.10 & 0.992 \\
\hline Hashimoto's thyroiditis & (yes vs. no) & 1.22 & 0.83 & 1.81 & 0.311 \\
\hline \multirow[t]{4}{*}{ The number of CLNM } & & & & & $<0.001^{\mathrm{a}}$ \\
\hline & 0 & 1 & & & \\
\hline & $1-3$ & 3.31 & 2.13 & 5.15 & $<0.001$ \\
\hline & $>3$ & 12.24 & 5.98 & 25.06 & $<0.001$ \\
\hline TSH value & & 0.98 & 0.86 & 1.11 & 0.711 \\
\hline
\end{tabular}

${ }^{a}$ means the global $p$-values; CLNM central lymph node metastasis

from 9 to 80 years old). The average tumor size was $1.34 \pm 1.02 \mathrm{~cm}$, ranging from 0.1 to $6 \mathrm{~cm}$. The range of TSH value was $0.001-14.68 \mathrm{uIU} / \mathrm{mL} .767$ cases were unilateral PTC, among which 679 cases were solitary, 88 cases were multifocality. There were 199 bilateral PTC cases. All patients underwent CLND, CLNM was found in $367(38.0 \%)$ cases. 420 patients underwent the functional LLND, 211 cases had LLNM, including 155 cases with LLNM and CLNM simultaneously and 56 cases with skip metastasis. Among the solitary cases, LLNM occurred in 130 cases, of which 36 cases had skip metastasis. Surgical complications included: 138 cases of transient hypoparathyroidism(14.3\%), 12 cases of permanent hypoparathyroidism(1.2\%), 9 cases of unilateral vocal cord paralysis $(0.9 \%), 2$ cases of bilateral vocal cord paralysis $(0.2 \%), 5$ cases of postoperative hemorrhage $(0.5 \%)$, and 8 cases of chylous leakage $(0.8 \%)$. Postoperative radioiodine therapy was performed on 252 patients. All patients were followed up after surgery until February 2018. The median follow-up time was 40 months (range, 25-61 months). During the follow-up period, none of patients died. 15 cases (1.6\%) experienced recurrence, including 12 cases with lymph node recurrence and 3 cases with thyroid recurrence. The patients with disease recurrence received an additional surgery.

\section{Risk factors for CLNM}

Univariate analysis showed that CLNM was significantly associated with age, male, tumor size, multifocality, bilateral location of tumors in the lobes, ETE and US features as intra-nodular vascularity or microcalcification $(P<0.05)$. However, distant metastasis, HT, the TSH value and US features as hypoechoic solid nodules, irregular shape or infiltrative margins were not 
significantly associated with CLNM $(P>0.05)$ (Tables 1 and 2 ). The multivariate analysis showed age $\leq 45$ years old, male, tumor size $>1.0 \mathrm{~cm}$, ETE and US features as microcalcification were the independent risk factors for CLNM $(P<$ 0.05) (Table 3).

\section{Risk factors for LLNM}

In 420 patients who underwent LLND, we analyzed the risk factors for LLNM. The univariate analysis showed that LLNM was statistically significant associated with age, tumor size, ETE and CLNM $(P<0.05)$. LLNM was not significantly related with gender, US features, tumor number, unilateral or bilateral location of tumors, distant metastasis, HT, or the TSH value $(P>0.05)$ (Tables 4,5$)$. We found that there was a significant difference in incidence of LLNM between PTC with and without CLNM. In order to further study the relationship between the number of CLNM and the incidence of LLNM, we made ROC curve to determine the critical value of the number of CLNM for predicting LLNM in 234 cases with CLNM. As shown in Fig. 1, the cutoff value of the number of CLNM was 2.5 (Sensitivity $=0.535$, Specificity $=$ 0.722 , AUC $=0.669, P<0.05)$. Therefore we grouped the number of CLNM as: none, $1-3$ and $>3$ in all models for LLNM. In the multivariate analysis, we found that only CLNM was the risk factor for LLNM, and with the increase of the number of CLNM, the OR value increased, the OR value of the number of $C L N M>3(O R=$ 9.27) was more than 3 times that of the number of CLNM equal to $1-3(\mathrm{OR}=2.96)$, which suggested that the risk of LLNM increased significantly with the increase of the number of CLNM $(P<0.05)$ (Table 6).

\section{The features of the LLNM}

In 211 cases with LLNM confirmed by pathology, the metastasis rates of level III (66.8\%) and IV (67.3\%) were significantly higher than that of level II $(42.2 \%)$ and V (21.3\%) $(P<0.05)$, but the difference between level III and IV was not statistically significant $(P>0.05)$. So, LLNM most likely occurs in level III and IV (Table 7). Moreover, lymph metastasis often involved multiple levels in the lateral compartment, multiple level lymph node metastasis was found in 129 (61.1\%) cases (4 levels in 18 cases, 3 levels in 40 cases and 2 levels in 71 cases). Single level lymph node metastasis in lateral compartment occurred in $82(38.9 \%)$ cases (12 cases in level II, 31 cases in level III, 35 cases in level IV and 4 cases in level V).

To determine whether the location of the tumor is related to the occurrence of LLNM, we analyzed LLNM in 272 patients with solitary tumor who underwent LLND. We found that tumor located in the upper $1 / 3$ of the lobe had the highest LLNM incidence $(60 \%)(P<0.05)$ (Table 8). To determine whether the location of the

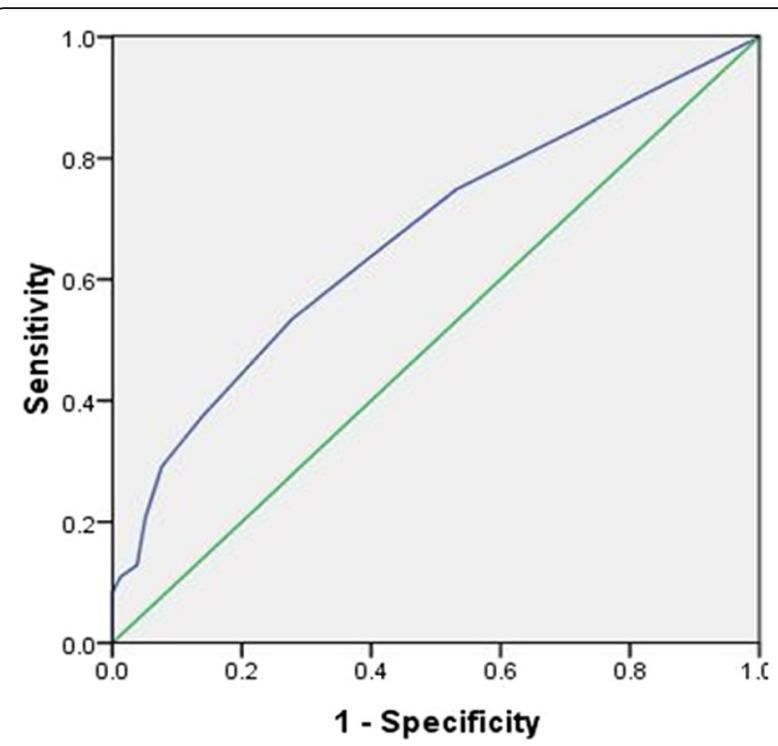

Fig. 1 Receiver operating characteristic curve analysis of the number of central lymph node metastasis for predicting lateral lymph node metastasis. The results of ROC showed that the cutoff value of the number of central lymph node metastasis was 2.5 , which was the optimal point to distinguish between PTC with and without lateral lymph node metastasis. At this value, the sensitivity was $53.5 \%$ and the specificity was $72.2 \%$; AUC was 0.669 , and the $95 \%$ CI was $0.599-0.739$

tumor was related to the level in lateral compartment of lymph node metastasis, 130 cases of solitary tumor with lateral lymph node metastasis were analyzed. We found that the location of the tumor was not related to the level in lateral compartment of lymph node metastasis $(P>0.05)$ (Table 9).

Table 6 Multivariate analysis of risk factors for lateral lymph node metastasis

\begin{tabular}{|c|c|c|c|c|c|}
\hline & & \multirow[t]{2}{*}{ OR } & \multicolumn{2}{|l|}{$95 \% \mathrm{Cl}$} & \multirow[t]{2}{*}{$P$ value } \\
\hline & & & Lower & Upper & \\
\hline \multirow[t]{5}{*}{ Age (years) } & & & & & $0.447^{a}$ \\
\hline & $\leq 35$ & 1.64 & 0.87 & 3.09 & 0.125 \\
\hline & $35-45$ & 1.26 & 0.66 & 2.40 & 0.478 \\
\hline & $45-55$ & 1.46 & 0.78 & 2.75 & 0.236 \\
\hline & $>55$ & 1 & & & \\
\hline \multirow[t]{5}{*}{ Tumor size(cm) } & & & & & $0.060^{\mathrm{a}}$ \\
\hline & $\leq 0.5$ & 1 & & & \\
\hline & $0.5-1.0$ & 1.57 & 0.67 & 3.63 & 0.297 \\
\hline & $1.0-2.0$ & 1.94 & 0.84 & 4.51 & 0.121 \\
\hline & $>2.0$ & 3.03 & 1.24 & 7.44 & 0.015 \\
\hline Extrathyroidal extension & (yes vs. no) & 1.26 & 0.78 & 2.02 & 0.350 \\
\hline \multirow[t]{4}{*}{ The number of CLNM } & & & & & $<0.001^{\mathrm{a}}$ \\
\hline & 0 & 1 & & & \\
\hline & $1-3$ & 2.96 & 1.87 & 4.70 & $<0.001$ \\
\hline & $>3$ & 9.27 & 4.38 & 19.63 & $<0.001$ \\
\hline
\end{tabular}

a means the global $p$-values; CLNM central lymph node metastasis 
Table 7 The incidence of lateral lymph node metastasis in different sites of lateral cervical compartment

\begin{tabular}{|c|c|c|c|c|c|}
\hline \multirow{2}{*}{$\begin{array}{l}\text { The sites of } \\
\text { lateral } \\
\text { compartment }\end{array}$} & \multicolumn{2}{|c|}{ Lateral lymph node metastasis } & \multirow{2}{*}{$\begin{array}{l}\text { Positive } \\
\text { rate }\end{array}$} & \multirow[t]{2}{*}{$x^{2}$} & \multirow[t]{2}{*}{$P$ value } \\
\hline & No & yes & & & \\
\hline & & & & 123.60 & $<0.001$ \\
\hline Level ॥ & 122 & 89 & $42.2 \%$ & & $<0.001^{\mathrm{a}},<0.001^{\mathrm{b}}, 0.918^{\mathrm{c}}$ \\
\hline Level III & 70 & 141 & $66.8 \%$ & & $<0.001^{d},<0.001^{e},<0.001^{f}$ \\
\hline Level IV & 69 & 142 & $67.3 \%$ & & \\
\hline Level V & 166 & 45 & $21.3 \%$ & & \\
\hline
\end{tabular}

aLevel II vs. Level III, 'bevel II vs. Level IV, ' Level III vs.Level IV, 'Level II vs. Level V,

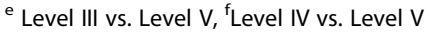

We also found that in 130 cases of solitary tumor with LLNM, 36 cases did not have CLNM, that is the socalled "skip metastasis", which have negative ipsilateral CLNM and positive ipsilateral LLNM. Further analysis found that tumors located in upper $1 / 3$ of the lobe had the highest skip metastasis incidence $(P<0.05)$, however, the location of the tumor was not related to the level in lateral compartment of skip metastasis (Tables 10,11).

\section{Discussion}

Although PTC is the most common pathological type of thyroid carcinoma with a 10-year survival exceeding $90 \%$ [7], previous studies found that cervical lymph node metastasis was common for PTCs and $40-90 \%$ of all PTCs could occur cervical lymph node metastasis $[1,8-10]$. It is widely accepted that cervical lymph node metastasis is a major cause of the local recurrence of PTC and it may also influence patients' survival [11-13]. Study showed reoperation for PTC recurrence was relatively difficult and might significantly increase the surgical complications which would affect patient's quality of life [14]. So, the treatment of cervical lymph nodes during initial operation is very important for the prognosis of patients. At present, there is still controversy about whether prophylactic CLND and the extent of therapeutic LLND. The main reasons for the controversy are as follows: first, CLND has potential higher incidence of complications and uncertainty of improved outcome; second, there is no evidence for what extent of LLND is the most appropriate for the management of LLNM.
Therefore, for guiding cervical lymph node dissection, it is of great significance to explore the properties and risk factors of cervical lymph node metastasis in PTC patients.

\section{Risk factors for CLNM}

Same with some of the previous results, in our study male was a risk factor for CLNM [15-19], which suggested that CLNM had a gender tendency. In males patients, physical examination and imaging evaluation of cervical lymph node status should be emphasized preoperatively. Whether age is related to CLNM, the current findings are not consistent. Liu et al [20] found that CLNM were not correlated with age, while other studies reported that age $<45$ years old was a risk factor for CLNM [17-19]. In this study, we found that younger age was associated with a higher odds ratio of CLNM, and age $\leq 45$ years old was independent risk factor for CLNM, which suggested that CLNM should be noticed in the younger patients.

In this study, we found that microcalcification on the US image was a risk factor for CLNM. Microcalcification is a calcium salt deposition due to hyperplasis of blood vessels and fibrous, reflecting rapid growth of cancer cells. Therefore, if microcalcification is found in the nodules, the lymph node status in central region should be assessed more carefully [21].

Multifocality, bilateral tumor and ETE were already included in previous studies as clinicopathological characteristics, there were studies showing that multifocality,

Table 8 Analysis about the tumor location and lateral lymph node metastasis

\begin{tabular}{|c|c|c|c|c|c|}
\hline \multirow[t]{2}{*}{ Tumor location } & \multicolumn{2}{|c|}{ lateral lymph node metastasis } & \multirow{2}{*}{$\begin{array}{l}\text { Positive } \\
\text { rate }\end{array}$} & \multirow[t]{2}{*}{$x^{2}$} & \multirow[t]{2}{*}{$P$ value } \\
\hline & $\overline{\mathrm{No}}$ & Yes & & & \\
\hline & & & & 11.423 & 0.022 \\
\hline Upper $1 / 3$ of the lobe & 38 & 57 & $60.0 \%$ & & \\
\hline Middle $1 / 3$ of the lobe & 34 & 20 & $37.0 \%$ & & \\
\hline Lower $1 / 3$ of the lobe & 47 & 29 & $38.2 \%$ & & \\
\hline Isthmus & 14 & 13 & $48.1 \%$ & & \\
\hline Whole & 9 & 11 & $5.5 \%$ & & \\
\hline
\end{tabular}


Table 9 Relation between tumor location and the sites of lateral lymph node metastasis

\begin{tabular}{|c|c|c|c|c|c|c|}
\hline \multirow[t]{2}{*}{ Tumor location } & \multicolumn{4}{|c|}{ The site of lateral lymph node metastasis } & \multirow[t]{2}{*}{$x^{2}$} & \multirow{2}{*}{$\begin{array}{l}P \\
\text { value }\end{array}$} \\
\hline & Level II & Level III & Level IV & Level V & & \\
\hline & & & & & 9.621 & 0.649 \\
\hline Upper $1 / 3$ of the lobe ( $n=57$ cases) & 34 & 38 & 36 & 15 & & \\
\hline Middle $1 / 3$ of the lobe ( $n=20$ cases) & 5 & 10 & 18 & 5 & & \\
\hline Lower $1 / 3$ of the lobe ( $n=29$ cases) & 8 & 16 & 19 & 5 & & \\
\hline Isthmus ( $n=13$ cases) & 3 & 8 & 10 & 2 & & \\
\hline Whole $(n=11$ cases $)$ & 4 & 7 & 10 & 2 & & \\
\hline
\end{tabular}

bilateral tumor and ETE were the risk factors for CLNM $[17,22-24]$, but our study showed that ETE was the risk factor for CLNM, which may be due to that once the tumor cells invade the thyroid capsule, it is easy to transfer to the surrounding lymph nodes along the rich lymphatic tissue around the capsule.

Tumor size was always considered as an important predictive factor for cervical lymph node metastasis in PTC, but the cutoffs were different. Ahn et al [18] showed that tumor size $\geq 1 \mathrm{~cm}$ was the risk factor for CLNM, while Yan et al [17] considered that tumor size $\geq 0.25 \mathrm{~cm}$. Furthermore, some studies reported that cervical lymph node metastasis was positively related to the primary tumor's size, as the size of the tumor increased, the incidence of cervical lymph node metastasis increased $[17,19,25]$. Our study divided the tumor size into 4 groups based on the AJCC staging system and the definition of PTMC. The multivariate analysis showed that the larger tumor was associated with an increased odds of CLNM, and tumor size $>1.0 \mathrm{~cm}$ was the independent risk factor for CLNM. So we considered that the tumor size $>1.0 \mathrm{~cm}$ was threshold for CLNM.

\section{Features and risk factors for LLNM}

There were many studies about the features and the risk factors for LLNM, but few of them had comprehensive clinicopathological properties, and the results of those studies were controversy. Zhang et al [16] reported that ETE, bilateral tumor and CLNM were risk factors for

Table 10 Analysis between the tumor location and skip metastasis

\begin{tabular}{llllll}
\hline Tumor location & \multicolumn{2}{l}{ Skip metastasis } & Metastasis & $x^{2}$ & $P$ value \\
\cline { 2 - 3 } & No & Yes & rate & & \\
\hline Upper $1 / 3$ of the lobe & 35 & 22 & $38.6 \%$ & & \\
Middle $1 / 3$ of the lobe & 18 & 2 & $10.0 \%$ & & \\
Lower 1/3 of the lobe & 21 & 8 & $27.6 \%$ & & \\
Isthmus & 9 & 4 & 30.021 & \\
Whole & 11 & 0 & $0 \%$ & \\
\hline
\end{tabular}

LLNM. Niel et al [26] considered that tumor located in upper pole, CLNM, and tumor size $>1.5 \mathrm{~cm}$ were the risk factors for LLNM, but Lin et al [19] considered that CLNM wasn't risk factor for LLNM. In this study, we found that only CLNM was the independent risk factor for LLNM; and the OR value increased with the increase of the number of CLNM, the OR value of the number of $\mathrm{CLNM}>3(\mathrm{OR}=9.27)$ was more than 3 times that of the number of CLNM equal to $1-3(\mathrm{OR}=2.96)(P<0.05)$, which suggested that CLNM number $>3$ was much more prone to LLNM than CLNM number equal to 13. So when the number of CLNM $>3$, the LLND should be more actively performed.

To date, the extent of therapeutic lateral neck dissection for PTC remains unclear. Several authors have reported that PTC metastasis is generally present at level II to $\mathrm{V}$ in lateral compartment, and lateral neck dissection including levels II to $\mathrm{V}$ is necessary for complete clearance of lateral neck metastasis [27-29]. But some authors raise objections to routine level $\mathrm{V}$ dissection for PTC patients with lateral compartment lymph node metastasis [30, 31]. In our study, lymph node metastasis in the lateral compartment occurred mostly in level III and $\mathrm{IV}$, and multiple levels involvement was common. Our data consistent with the idea that extent of lateral central neck dissection should include levels II, III, IV and V.

In most of the previous studies, the solitary tumor location was divided into 4 groups as the upper $1 / 3$, middle $1 / 3$, lower $1 / 3$ and isthmus, the relationship between tumor location and LLNM was examined [16, 32, 33]. Zhang et al [16] demonstrated that the primary tumor in the upper $1 / 3$ of the lobe had a lower risk for CLNM and a higher risk for LLNM. Qubain et al [33] showed that tumor in the upper $1 / 3$ of the lobe was more vulnerable to transfer to lymph node in the upper cervical region, and the tumor in the isthmus and the lower $1 / 3$ of the lobe was more likely to transfer to lymph node in the lower cervical region. Furthermore, it has been found that the skip metastasis of LLNM often happens in tumor located in the upper $1 / 3$ of the lobe [16, 34]. Lei et al [34] reported that 39 patients with lymph node skip metastasis in their study had a much higher rate of 
Table 11 Relation between tumor location and the sites of skip metastasis

\begin{tabular}{|c|c|c|c|c|c|c|}
\hline \multirow[t]{2}{*}{ Tumor location } & \multicolumn{4}{|c|}{ The site of skip metastasis } & \multirow[t]{2}{*}{$x^{2}$} & \multirow{2}{*}{$\begin{array}{l}P \\
\text { value }\end{array}$} \\
\hline & Level II & Level III & Level IV & Level V & & \\
\hline & & & & & 6.689 & 0.674 \\
\hline Upper $1 / 3$ of the lobe ( $n=22$ cases) & 15 & 10 & 11 & 3 & & \\
\hline Middle $1 / 3$ of the lobe ( $n=2$ cases) & 1 & 1 & 2 & 1 & & \\
\hline Lower $1 / 3$ of the lobe ( $n=8$ cases) & 1 & 2 & 4 & 2 & & \\
\hline Isthmus ( $n=4$ cases) & 1 & 1 & 3 & 1 & & \\
\hline
\end{tabular}

level II but a lower rate of Level III, IV and V lymph node involvement. In our study, the solitary tumor location was divided into 5 groups as the upper $1 / 3$, middle1/ 3 , lower $1 / 3$, isthmus and whole which means tumor occupying the whole lobe. We found that among the 272 solitary tumor patients who underwent LLND, tumor located in the upper $1 / 3$ of the lobe had the highest incidence of LLNM. Furthermore, by analyzing 130 solitary tumor cases with LLNM, we found skip metastasis was more vulnerable to occur in tumor located in upper $1 / 3$ of the lobe, which might be due to the upper $1 / 3$ lymphatic vessels of the lobe draining into the deep lateral lymph nodes, which are in common carotid artery bifurcation along the superior thyroid artery and vein. However, we didn't find that the location of the tumor was related to the level in lateral compartment of lymph node metastasis and skip metastasis in our study, which may be due to the small sample of solitary tumor with LLNM and skip metastasis, further investigation should be done by expanding the sample.

In this study, the positive rate of metastasis was not high in patients who underwent lateral neck dissection, only $50.3 \%$. The possible reason for this is that we assessed lymph node metastasis primarily by ultrasound, contrast enhanced CT and FNA were only used in very few patients during the study. The sensitivity and specificity of ultrasound in assessing cervical lymph node metastasis is not high, and the results of ultrasound depends on the operator's diagnostic experience to a large extent, which leads to a low positive rate of lateral neck dissection performed according to ultrasound. To solve this problem, we now routinely perform cervical contrast enhanced CT, ultrasound-suspected metastatic lymph nodes are further assessed by FNA, which can reduce unnecessary LLND. The combination of the US/ CT/FNA/intraoperative biopsy could achieve a very high sensitivity and specificity in assessing cervical lymph node metastasis.

\section{Conclusions}

In summary, we considered that prophylactic CLND should be performed in patients with risk factors as male, age $\leq 45$ years old, tumor size $>1 \mathrm{~cm}$, and ETE and US features as microcalcification. LLND should be more actively performed in patients with the number of CLNM $>3$. Extent of LLND should include levels II, III, IV and V. Lymph nodes status should be preoperatively assessed by US, CT and FNA. For tumor located in the upper $1 / 3$ of the lobe, LLNM and skip metastasis was likely occurred, so lateral lymph node should be noticed when lymph node status was preoperatively evaluated by imaging examination.

\section{Abbreviations}

AJCC: American Joint Committee on Cancer; CLND: Central lymph node dissection; CLNM: Central lymph node metastasis; ETE: Extrathyroidal extension; HT: Hashimoto's thyroiditis; LLND: Lateral lymph node dissection; LLNM: Lateral lymph node metastasis; PTC: Papillary thyroid carcinoma;

TNM: Tumor node metastasis; TSH: Thyroid stimulating hormone

\section{Acknowledgements}

We thank Li Jiang for his help with the revision of manuscript.

\section{Authors' contributions}

ZL and $C L$ designed the study and drafted the manuscript. CX, JC and XL collected the data. ZF and QG performed statistical analysis. All authors read and approved the final manuscript.

\section{Funding}

This study was funded by the National Natural Science Foundation of China (grant number 81672644). The funding body had no role in the study design, data collection, analysis, interpretation of data or in writing the manuscript.

Availability of data and materials

All data analyzed during this study are available from the corresponding author on reasonable request.

Ethics approval and consent to participate

This study was approved by the Ethics Committee of Shengjing Hospital of China Medical University. The requirement for informed consent was waived given the retrospective nature of the data, which was approved by the Ethics Committee of Shengjing Hospital of China Medical University.

\section{Consent for publication}

Not applicable.

\section{Competing interests}

The authors declare that they have no competing interests.

Received: 10 March 2019 Accepted: 13 June 2019

Published online: 25 June 2019

References

1. Lundgren Cl, Hall P, Dickman PW, Zedenius J. Clinically significant prognostic factors for differentiated thyroid carcinoma: a population-based, nested case-control study. Cancer. 2006;106(3):524-31.

2. Moo TA, McGill J, Allendorf J, Lee J, Fahey T 3rd, Zarnegar R. Impact of prophylactic central neck lymph node dissection on early recurrence in papillary thyroid carcinoma. World J Surg. 2010;34(6):1187-91. 
3. Forest VI, Clark JR, Ebrahimi A, Cho EA, Sneddon L, Gao K, O'brien CJ. Central compartment dissection in thyroid papillary carcinoma. Ann Surg. 2011;253(1):123-30.

4. Wang W, Gu J, Shang J, Wang K. Correlation analysis on central lymph node metastasis in 276 patients with cN0 papillry thyroid carcinoma. Int J Clin Exp Pathol. 2013:6(3):510-5.

5. Goropoulos A, Karamoshos K, Christodoulou A, Ntitsias T, Paulou K, Samaras A, Xirou P, Efstratiou I. Value of the cervical compartments in the surgical treatment of papillary thyroid carcinoma. World J Surg. 2004:28(12):1275-81.

6. Qu N, Zhang L, Lin DZ, Ji QH, Zhu YX, Wang Y. The impact of coexistant Hashimoto's thyroiditis on lymph node metastasis and prognosis in papillary thyroid microcarcinoma. Tumour Biol. 2016;37(6):7685-92.

7. Malterling RR, Andersson RE, Falkmer S, Falkmer U, Niléhn E, Järhult J. Differentiated thyroid cancer in a Swedish country--long-term results and quality of life. Acta Oncol. 2010;49(4):454-9.

8. Jiang LH, Chen C, Tan ZLXX, Hu SS, Wang QL, Hou XX, Cao J, Ge MH. Clinical characteristics related to central lymph node metastasis in CNO papillary thyroid carcinoma: a retrospective study of 916 patients. Int J Endocrinol. 2014;2014:385787.

9. So YK, Son Yl, Hong SD, Seo MY, Baek CH, Jeong HS, Chung MK. Subclinical lymph node metastasis in papillary thyroid microcarcinoma: a study of 551 resections. Surgery. 2010;148(3):526-31.

10. Lee YM, Sung TY, Kim WB, Chung KW, Yoon JH, Hong SJ. Risk factors for recurrence in patients with papillary thyroid carcinoma undergoing modified radical neck dissection. Br J Surg. 2016;103(8):1020-5.

11. Qiao N, Bai X, Wang G, Sun B, Wu L. Controversy and progress on prophylactic central neck dissection in cNO papillary thyroid carcinoma. Chinese Journal of General Surgery. 2016;25(5):729-34 in Chinese.

12. Hay ID, Hutchinson ME, Gonzalez-Losada T, Mclver B, Reinalda ME, Grant CS, Thompson GB, Sebo TJ, Goellner JR. Papillary thyroid microcarcinoma: a study of 900 cases observed in a 60-year period. Surgery. 2008;144(6):980-7.

13. Pisanu A, Reccia I, Nardello O, Uccheddu A. Risk factors for nodal metastasis and recurrence among patients with papillary thyroid microcarcinoma: differences in clinical relevance between nonincidental and incidental tumors. World J Surg. 2009;33(3):460-8.

14. Nixion IJ, Wang LY, Ganly I, Patel SG, Morris LG, Migliacci JC, Tuttle RM, Shah JP, Shaha AR. Outcomes for patients with papillary thyroid cancer who do not undergo prophylactic central neck dissection. Br J Surg. 2016;103(3): 218-25.

15. Ahn JH, Lee JH, Yi JS, Shong YK, Hong SJ, Lee DH, Choi CG, Kim SJ. Diagnostic accuracy of $\mathrm{CT}$ and ultrasonography for evaluating metastatic cervical lymph nodes in patients with thyroid cancer. World J Surg. 2008; 32(7):1152-8.

16. Zhang L, Wei WJ, Ji QH, Zhu YX, Wang ZY, Wang Y, Huang CP, Shen Q, Li DS, Wu Y. Risk factors for neck nodal metastasis in papillary thyroid microcaicinoma:a study of 1066 patients. J Clin Endocrinol Metab. 2012; 97(4):1250-7.

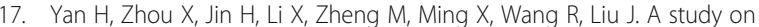
central lymph node metastasis in $543 \mathrm{cn} 0$ papillary thyroid carcinoma patients. Int J Endocrinol. 2016;2016:1878194.

18. Ahn BH, Kim JR, Jeong HC, Lee JS, Chang ES, Kim YH. Predictive factors of central lymph node metastasis in papillary thyroid carcinoma. Ann Surg Treat Res. 2015;88(2):63-8.

19. Lin DZ, Qu N, Shi RL, Lu ZW, Ji QH, Wu WL. Risk prediction and clinical model building for lymph node metastasis in papillary thyroid microcarcinoma. Onco Targets Ther. 2016;9:5307-16.

20. Liu Z, Wang L, Yi P, Wang CY, Huang T. Risk factors for central lymph node metastasis of patients with papillary thyroid microcarcinoma: a metaanalysis. Int J Clin Exp Pathol. 2014;7(3):932-7.

21. lannuccilli JD, Cronan JJ, Monchik JM. Risk for malignancy of thyroid nodules as assessed by sonogrgphic criteria: the need for biopsy. J Ultrasound Med. 2004;23(11):1455-64.

22. Liang $\mathrm{K}, \mathrm{He} \mathrm{L}$, Dong W, Zhang H. Risk factors of central lymph node metastasis in cNO papillary thyroid carcinoma: a study of 529 patients. Med Sci Monit. 2014:20:807-11.

23. Xu D, Lv X, Wang S, Dai W. Risk factors for predicting central lymph node metastasis in papillary thyroid microcarcinoma. Int J Clin Exp Pathol. 2014; 7(9):6199-205.

24. Liu W, Cheng R, Su Y, Diao C, Qian J, Zhang J, Ma Y, Fan Y. Risk factors of central lymph node metastasis of papillary thyroid carcinoma a single- center retrospective analysis of 3273 cases. Medicine (Baltimore). 2017 96(43):e8365.

25. Gomez NR, Kouniavsky G, Tsai HL, Somervell H, Pai SI, Tufano RP, Umbricht C, Kowalski J, Dackiw AP, Zeiger MA. Tumor size and presence of calcification on ultrasonography are pre-operative predictors of lymph node metastases in patients with papillary thyroid cancer. J Surg Oncol. 2011; 104(6):613-6.

26. Nie X, Tan Z, Ge M, Jiang L, Wang J, Zheng C. Risk factors analyses for lateral lymph node metastases in papillary thyroid carcinomas: a retrospective study of 356 patients. Arch Endocrinol Metab. 2016;60(5):4929.

27. Keum HS, Ji YB, Kim JM, Jeong JH, Choi WH, Ahn YH, Tae K. Optimal surgical extent of lateral and central neck dissection for papillary thyroid carcinoma located in one lobe with clinical lateral lymph node metastasis. World J Surg Oncol. 2012:10:221.

28. Kupferman ME, Weinstock YE, Santillan AA, Mishra A, Roberts D, Clayman GL, Weber RS. Predictors of level V metastasis in well-differentiated thyroid cancer. Head Neck. 2008;30(11):1469-74.

29. Pingpank JF Jr, Sasson AR, Hanlon AL, Friedman CD, Ridge JA. Tumor above the spinal accessory nerve in papillary thyroid cancer that involves lateral neck nodes: a common occurrence. Arch Otolaryngol Head Neck Surg. 2002:128(11):1275-8.

30. Caron NR, Tan YY, Ogilvie JB, Triponez F, Reiff ES, Kebebew E, Duh QY, Clark $\mathrm{OH}$. Selective modified radical neck dissection for papillary thyroid cancer-is level I, II, and V dissection always necessary? World J Surg. 2006;30(5):83340.

31. Lim YC, Choi EC, Yoon YH, Koo BS. Occult lymph node metastases in neck level $V$ in papillary thyroid carcinoma. Surgery. 2010;147(2):241-5.

32. Lee YS, Shin SC, Lim YS, Lee JC, Wang SG, Son SM, Kim IJ, Lee BJ. Tumor location-dependent skip lateral cervical lymph node metastasis in papillary thyroid cancer. Head Neck. 2014;36(6):887-91.

33. Qubain SW, Nakano S, Baba M, Takao S, Aikou T. Distribution of lymph node micrometastasis in pN0 well-differentiated thyroid carcinoma. Surgery. 2012; 131(3):249-56

34. Lei J, Zhong J, Jiang K, Li Z, Gong R, Zhu J. Skip latetal lymph node metastasis leaping over the central neck compartment in papillary thyroid carcinoma. Oncotarget. 2017;8(16):27022-33.

\section{Publisher's Note}

Springer Nature remains neutral with regard to jurisdictional claims in published maps and institutional affiliations.

Ready to submit your research? Choose BMC and benefit from:

- fast, convenient online submission

- thorough peer review by experienced researchers in your field

- rapid publication on acceptance

- support for research data, including large and complex data types

- gold Open Access which fosters wider collaboration and increased citations

- maximum visibility for your research: over $100 \mathrm{M}$ website views per year

At $\mathrm{BMC}$, research is always in progress.

Learn more biomedcentral.com/submission 